\title{
Predicting operative mortality in octogenarians for isolated coronary artery bypass grafting surgery: a retrospective study
}

Jessica G. Y. Luc ${ }^{1}$, Michelle M. Graham²,3, Colleen M. Norris ${ }^{1,2,3}$, Sadek Al Shouli ${ }^{1,2}$, Yugmel S. Nijjar ${ }^{1}$ and Steven R. Meyer ${ }^{1,2^{*}}$

\begin{abstract}
Background: Available cardiac surgery risk scores have not been validated in octogenarians. Our objective was to compare the predictive ability of the Society of Thoracic Surgeons (STS) score, EuroSCORE I, and EuroSCORE II in elderly patients undergoing isolated coronary artery bypass grafting surgery (CABG).

Methods: All patients who underwent isolated CABG (2002 - 2008) were identified from the Alberta Provincial Project for Outcomes Assessment in Coronary Heart Disease (APPROACH) registry. All patients aged 80 and older $(n=304)$ were then matched 1:2 with a randomly selected control group of patients under age 80 ( $n=608$ of 4732). Risk scores were calculated. Discriminatory accuracy of the risk models was assessed by plotting the areas under the receiver operator characteristic (AUC) and comparing the observed to predicted operative mortality.

Results: Octogenarians had a significantly higher predicted mortality by STS Score ( $3 \pm 2 \%$ vs. $1 \pm 1 \% ; p<0.001)$, additive EuroSCORE ( $8 \pm 3 \%$ vs. $4 \pm 3 \% ; p<0.001)$, logistic EuroSCORE ( $15 \pm 14 \%$ vs. $5 \pm 6 \% ; p<0.001)$, and EuroSCORE II $(4 \pm 3 \%$ vs. $2 \pm 2 \% ; p<0.001)$ compared to patients under age 80 years. Observed mortality was $2 \%$ and $1 \%$ for patients age 80 and older and under age 80 , respectively $(p=0.323$ ). AUC revealed areas for STS, additive and logistic EuroSCORE I and EuroSCORE II, respectively, for patients age 80 and older $(0.671,0.709,0.694,0.794)$ and under age $80(0.829$, $0.750,0.785,0.845)$.

Conclusion: All risk prediction models assessed overestimated surgical risk, particularly in octogenarians. EuroSCORE II demonstrated better discriminatory accuracy in this population. Inclusion of new variables into these risk models, such as frailty, may allow for more accurate prediction of true operative risk.
\end{abstract}

Keywords: Cardiovascular research, Coronary artery disease, Risk prediction, Octogenarians Classification Codes: Cardiovascular Surgery, Coronary Artery Disease, Risk Stratification

\footnotetext{
* Correspondence: srmeyer@ualberta.ca

'Division of Cardiac Surgery, Department of Surgery, Faculty of Medicine and

Dentistry, University of Alberta, Edmonton, Canada

${ }^{2}$ Mazankowski Alberta Heart Institute, Edmonton, Canada

Full list of author information is available at the end of the article
}

\section{Ciomed Central}

(c) The Author(s). 2017 Open Access This article is distributed under the terms of the Creative Commons Attribution 4.0 International License (http://creativecommons.org/licenses/by/4.0/), which permits unrestricted use, distribution, and reproduction in any medium, provided you give appropriate credit to the original author(s) and the source, provide a link to the Creative Commons license, and indicate if changes were made. The Creative Commons Public Domain Dedication waiver (http://creativecommons.org/publicdomain/zero/1.0/) applies to the data made available in this article, unless otherwise stated. 


\section{Background}

Coronary artery disease is a leading cause of morbidity and mortality in octogenarian patients $[1,2]$. Octogenarians represent the fastest growing segment of our population; over $40 \%$ of the very elderly manifest cardiovascular disease [3]. The indications for coronary artery bypass grafting (CABG) surgery are well defined and the number of octogenarians being referred for surgical coronary revascularization is increasing [4]. Accurate risk stratification and the prediction of operative mortality is essential as this aids the clinical decision-making process, helps estimate the need for resources, facilitates proper patient counseling, informed consent, and allows for monitoring of surgeon and institution performance through risk-adjusted outcomes.

Risk-scoring algorithms based on both patient history and functional status have been established. The most widely used are the Society of Thoracic Surgeons Predicted Risk of Mortality (STS) score and the European System for Cardiac Operative Risk Evaluation (EuroSCORE) [5, 6]. Despite the acceptance of these risk scores in the context of CABG, there is little data on the performance of the revised EuroSCORE II in comparison to the established STS, additive EuroSCORE and the logistic Euroscore. Furthermore, these scores have not been validated to specifically predict operative mortality in octogenarians.

The aim of the current study was to evaluate and compare the performance of the recently introduced EuroSCORE II with its previous version EuroSCORE (additive and logistic) and the STS score in predicting perioperative mortality in patients age 80 and older undergoing isolated CABG at our institution.

\section{Methods}

\section{Patients and procedures}

We retrospectively reviewed 304 consecutive patients age 80 and older and a randomly selected cohort of adult patients under age $80(n=608$ of 4732) who underwent isolated CABG between January 2002 and December 2008 at the University of Alberta. The older group was compared in a 1:2 ratio to the younger group. Patients undergoing concomitant surgery (e.g., valve, vascular, or congenital) were excluded. All nonemergent cardiac surgery cases undergo multidisciplinary review at our institution. These multidisciplinary rounds include cardiac surgeons, interventional cardiologists and cardiologists. A comparison ratio of 1:2 was selected instead of $1: 1$ as our population of elderly patients is modest; a larger control group of younger patients generates a more normally distributed dataset for analysis.

The Alberta Provincial Project for Outcome Assessment in Coronary Heart Disease (APPROACH) database has been previously described [7]. In brief, APPROACH is a prospective clinical data collection initiative capturing all patients undergoing cardiac catheterization or cardiac surgery in the province of Alberta, Canada since 1995. The registry includes detailed individual patient demographic, medical, angiographic, surgical and postoperative information. Preoperative patient demographic and medical variables including risk factors, comorbidities, cardiac diagnostic and surgical procedural information are entered into the dataset. Patients captured by the registry are longitudinally followed for all cardiac-specific investigations, interventions and outcomes. Mortality is tracked through an Alberta Bureau of Vital Statistics data linkage [8]. The University of Alberta Health Research Ethics Board has approved the waiver of patient consent for this data registry (Pro00042669).

The APPROACH database was queried for pre, intra and postoperative data of the patients in this study. Risk scores were then calculated online using the official websites and calculators (STS score: http://riskcalc.sts.org/stswebriskcalc/ \#/calculate; additive and logistic EuroSCORE: http://euroscore.org/calcold.html; EuroSCORE II: http://euroscore.org/ calc.html). The simple additive EuroSCORE and the full logistic EuroSCORE, were included because both have been adopted in clinical practice for reasons of simplicity for the additive model and accuracy for the logistic model [9].

\section{Outcomes of interest}

The primary outcome of interest was perioperative mortality, defined as any death that occurred during the initial hospitalization or within 30 days of isolated CABG. The expected 30-day mortality based on the calculated STS score, EuroSCORE (additive and logistic), and EuroSCORE II were compared with the observed 30-day mortality.

\section{Statistical analysis}

Continuous variables were described as mean and standard deviation and categorical variables as percentages. Comparisons between continuous data were made with student $\mathrm{t}$-test or Mann-Whitney $\mathrm{U}$ test and comparisons between categorical data were made with Chi-square or Fisher's exact test where appropriate. Sensitivity and specificity of expected versus observed mortality were summarized by receiver operator curves and the area under the receiver operator characteristic (AUC). Net reclassification improvement (NRI) analysis was also performed to formally assess the various scores accuracy in predicting risk in both age groups. A $p$-value of less than 0.05 was considered significant. All statistical analyses were performed using Statistical Package for Social Sciences (SPSS Statistics, version 21, Chicago, Illinois). 


\section{Results}

From January 1, 2002 to December 31, 2008, a total of 4732 patients underwent isolated CABG at the University of Alberta. Of these, 304 patients were aged 80 years or older. Baseline characteristics are outlined in Table 1. In general, elderly patients had more comorbidities, cardiac risk factors and were more likely to undergo emergency surgery. Use of multiple arterial conduits is rare in Alberta. No patients in this octogenarian cohort received a third arterial graft.

Relative to younger patients, those aged 80 and older had a significantly higher mean predicted mortality by the STS Score ( $3 \pm 2 \%$ vs. $1 \pm 1 \%$; $p<0.001)$, additive EuroSCORE ( $8 \pm 3 \%$ vs. $4 \pm 3 \%$; p $<0.001)$, logistic EuroSCORE $(15 \pm 14 \%$ vs. $5 \pm 6 \%$; p $<0.001)$, and EuroSCORE II ( $4 \pm 3 \%$ vs. $2 \pm 2 \%$; p < 0.001) (Fig. 1). The total observed perioperative mortality of $2 \%$ for patients aged 80 years and older was not significantly different from the observed perioperative mortality of $1 \%$ for patients under age $80(p=0.323)$.

The receiver operator characteristic (ROC) for both patient groups are shown in Fig. $2 \mathrm{a}$ and b respectively. Patient's age 80 and older had an AUC for the STS score of $(0.672 ; p=0.151,95 \%$ confidence interval [CI] 0.459 to 0.883$)$, additive EuroSCORE $(0.709 ; p=0.079,95 \% \mathrm{CI}$ 0.523 to 0.896$)$, logistic EuroSCORE (0.694; $p=0.104$, 95\% CI 0.499 to 0.889 ) and EuroSCORE II (0.794; $p=0.014,95 \%$ CI 0.696 to 0.893$)$. Patients under age 80 had an AUC for the STS score of $(0.829 ; p=0.003$, 95\% CI 0.710 to 0.947), additive EuroSCORE (0.750; $p=0.023,95 \%$ CI 0.544 to 0.955$)$, logistic EuroSCORE $(0.785 ; p=0.010,95 \%$ CI 0.585 to 0.985$)$ and EuroSCORE II $(0.845 ; p=0.002,95 \%$ CI 0.709 to 0.980$)$. The $p$-value under the AUC represents the ability and accuracy of the score in predicting perioperative mortality in patients who undergo CABG surgery. Overall, all scores assessed underperformed patients age 80 and older compared, with EuroSCORE II demonstrating the best predictive ability in this group.

The net reclassification improvement index (NRI) of STS compared to EuroSCORE II was calculated. Area under the curve analysis demonstrates that the areas of the three curves are similar for patients under age 80, but different for patients age 80 and over where EuroSCORE II had the largest area. The Delong test indicates that the difference of the AUC between the three curves is not significant for both groups. However, NRI analysis reveals that EuroSCORE adds 16\% reclassification improvement compared to STS for age under 80, and $67 \%$ improvement for in those age 80 and older. The $67 \%$ improvement results from ability of EuroSCORE II to discriminate all 6 deaths, while STS is able to discriminate only half (3 out of 6 ) of deaths.

\section{Discussion}

We demonstrate in a large series of consecutive octogenarians undergoing isolated CABG that EuroSCORE II had the best performance for risk assessment among the tools available. However, the expected mortality calculated by all four risk scores overestimated perioperative risk for patients of all ages, most particularly in octogenarians.

Our study is unique in that it includes all four risk scores with a focused evaluation of their performance in isolated CABG surgery. This is particularly relevant given that octogenarians represent a growing proportion of patients being referred for CABG surgery [10]. Early studies report cardiac surgery operative mortality rates of up to $11 \%[11,12]$. Refinements in surgical technique and perioperative management has resulted in

Table 1 Baseline Demographics

\begin{tabular}{|c|c|c|c|}
\hline Variable & Under Age $80(n=608)$ & Age 80 and Older $(n=304)$ & P Value \\
\hline Age & 63.8 & 82.1 & $<0.001^{\natural}$ \\
\hline Gender (Female) & $92(15.1)$ & $78(25.7)$ & $0.001^{\natural}$ \\
\hline Body Surface Area & $1.94 \pm 0.17$ & $1.86 \pm 0.18$ & $<0.001^{\natural}$ \\
\hline Weight (kg) & $80.7 \pm 12.5$ & $74.8 \pm 11.9$ & $<0.001^{\natural}$ \\
\hline Renal Impairment & $116(19.0)$ & $55(18.0)$ & $0.044^{q}$ \\
\hline Hypertension & $452(74.3)$ & $243(79.9)$ & 0.062 \\
\hline Hypercholesterolemia & $519(85.4)$ & $211(69.4)$ & 0.839 \\
\hline Diabetes & $204(33.6)$ & $76(25.0)$ & $0.008^{q}$ \\
\hline Extracardiac Arteriopathy & $48(7.9)$ & $31(10.2)$ & 0.244 \\
\hline Reduced Left Ventricular Ejection Fraction & $340(55.9)$ & $137(45.1)$ & $0.001^{\natural}$ \\
\hline Cerebrovascular Disease & $44(7.2)$ & $40(13.2)$ & $<0.001^{\natural}$ \\
\hline Chronic Obstructive Pulmonary Disease & $65(10.7)$ & $41(13.5)$ & $<0.001^{\natural}$ \\
\hline Emergency Surgery & $16(2.6)$ & $12(3.9)$ & $0.001^{\natural}$ \\
\hline
\end{tabular}

Continuous data are reported as mean \pm standard deviation; categorical data are (\%) are presented by frequency. " Indicates significance $p<\mathrm{V} 0.05$ 


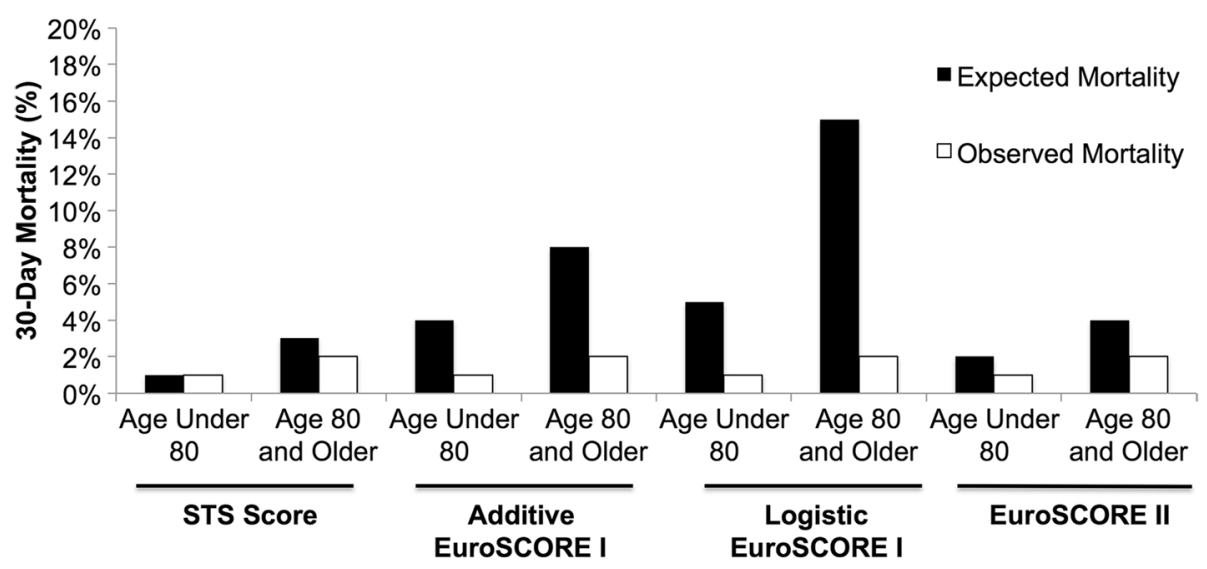

Fig. 1 STS risk score, additive EuroSCORE, logistic EuroSCORE, and EuroSCORE II overestimates operative mortality in patients age 80 and older. Expected 30-day mortality was compared to observed 30-day mortality in patients under the age of 80 and patients age 80 and older who underwent isolated CABG

significantly improved outcomes [13], as well, differences in observed operative mortality in other reports may stem from inherent country or population specific outcomes $[14,15]$. We report a low observed perioperative mortality of $2 \%$ in patients age 80 and older which is not different from existing contemporary reports $[4,16,17]$. Although elderly patients have worse early outcomes compared to younger patients, long-term outcomes for octogenarians at our institution after CABG are similar to, if not better than, the age-adjusted Canadian population. These are demonstrated by previously published reports on our cohort examining intermediate and long-term survival post-operatively for octogenarians compared to younger subjects $[4,18,19]$.

Accurate risk stratification facilitates improved patient selection, prevents complications [20], improves patient quality of life and can justify the cost effectiveness of the procedure [21]. However, risk models, although helpful and objective for operative risk assessment and clinical decision-making, are not without their limitations. The original EuroSCORE and EuroSCORE II were developed with a patient population mean age of 62.5 years and 64.9 years, respectively $[13,22]$. Our results show that all scores assessed significantly overestimated operative risk in octogenarians, and were well calibrated in patients under age 80 . This identified imprecision in operative risk prediction has important implications for clinical decision making in elderly patients.

Frailty has been shown to be an independent predictor for both postoperative complications and in-hospital mortality after adjusting for age [23]. It is estimated that $20 \%$ of octogenarians are frail [24]. Although considered difficult to quantify as compared to the comorbidity-based risk assessment models currently in use, several scores have emerged as an attempt to assess frailty including the Edmonton Frailty Scale, Comprehensive Assessment of Frailty test,
Fried Frailty Scale and others [24-26] These frailty scores are a multidimensional assessment of health and functional status incorporating sociodemographic, biomedical, cognitive capacity, independence with daily activities, social support and mood [27, 28].

Incorporating a quantitative measure of the degree of frailty can introduce objectivity to the assessment of biological status to complement conventional comorbidity risk assessment and improve the accuracy of operative risk assessment in the elderly. This would allow more accurate stratification of risk than current models and aid in selecting the most appropriate modality of intervention to best optimize outcomes for patients. In an age 70 and older population, Prudon et al. [29] demonstrated that the addition of gait speed to logistic EuroSCORE improved the accuracy of the model. Sundermann et al. [24] used a frailty score in addition to conventional risk scores and found frailty to only moderately correlate with STS and EuroSCORE risk models. Other investigators have demonstrated the utility of a frailty score in the preoperative assessment of their patients [24, 30]. Afilalo et al. demonstrate that both frailty and disability (as defined by a 5 - $\mathrm{m}$ gait speed $\geq 6$ seconds and the presence of 3 or more impairments on the Nagi scale) are complementary and additive to existing risk scores where inclusion of them improved the discrimination of the STS score [30]. Thus, incorporation of various risk factors specific to the elderly population as measures of physiological vulnerability may improve the effectiveness of cardiac surgical risk models [31].

Frailty is an emerging concept; collaborative efforts towards defining the optimal method towards measuring frailty and disability deserve further exploration. Multidisciplinary teams involving cardiac surgery, cardiology, geriatric medicine, physiotherapy and occupational therapy may help address the diverse elements 
a

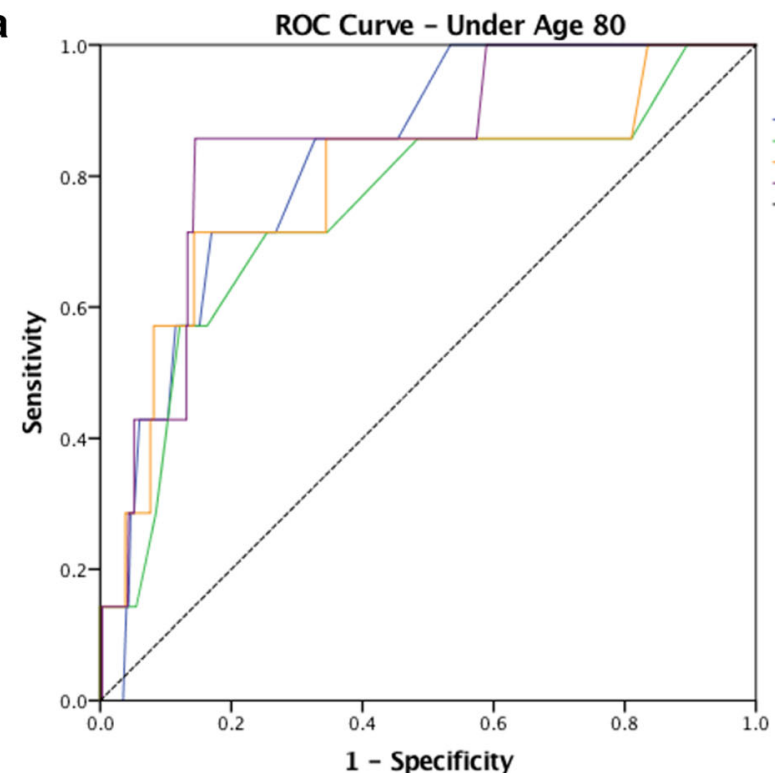

\begin{tabular}{|l|c|c|}
\hline & AUC & P-Value \\
\hline STS Score & 0.829 & 0.003 \\
\hline Additive Euroscore & 0.750 & 0.023 \\
\hline Logistic Euroscore & 0.785 & 0.010 \\
\hline Euroscore II & 0.845 & 0.002 \\
\hline
\end{tabular}

b

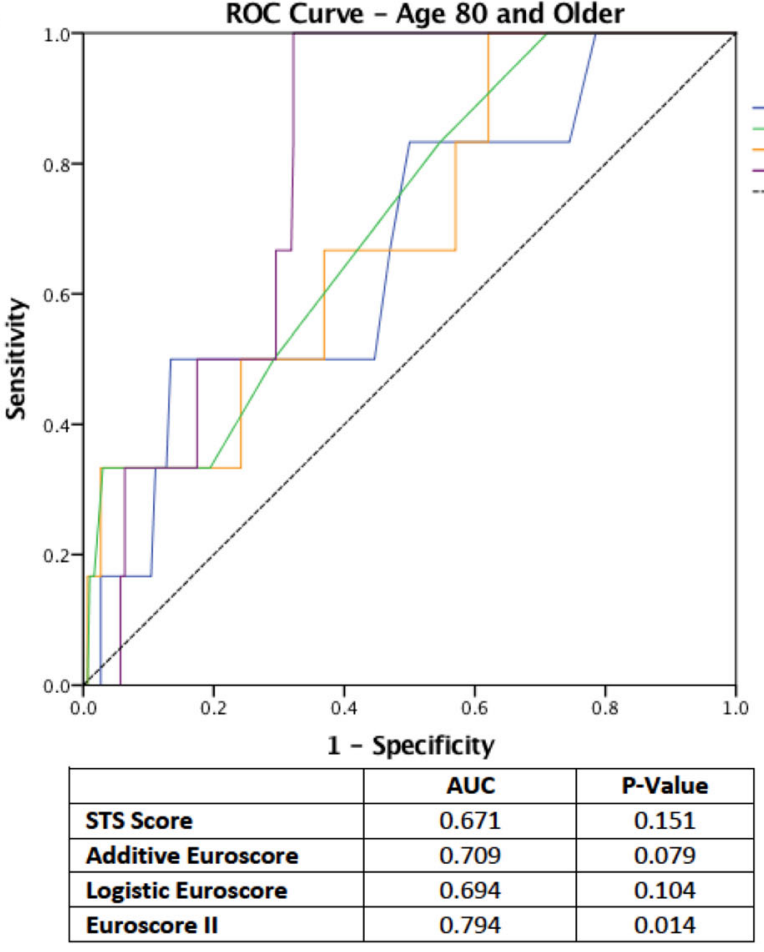

Source of the Curve

- STS Score

Additive Score

- Logistic Eurosco

--.- Reference Lin

$$
\text { . }
$$


specific to the elderly that contribute to increased risk [32]. A 64-slice-coronary computed tomography shows promise as a non-invasive alternative to the standard coronary angiography to detect CABG graft stenosis [33]. However, in a frail octogenarian population, symptoms and quality of life should be the driver for any further invasive or non-invasive investigations.

\section{Limitations}

There are several limitations to this study. First, this is a single institution study, thus our results may not apply to those from other institutions and countries. Second, the present study only included patients undergoing isolated CABG and the results cannot be extrapolated to patients undergoing other cardiac surgical procedures. Third, EuroSCORE II has introduced two variables, poor mobility and pulmonary artery pressure, which are not consistently recorded in the APPROACH database; therefore all patients were analyzed as not scoring for this risk factor. However, if these risks were present in our entire elderly cohort, the estimated risk of surgery would have further increased. Finally, our intention was neither to develop a new score nor to investigate the impact of individual variables on specific postoperative complications. While the predictive value for mortality differs considerably from that of morbidity for most of the variables included in the risk models [34], our analysis focused on the discriminatory ability of these scores in predicting perioperative mortality - which was what these risk scores were originally designed to achieve.

\section{Conclusion}

Currently, all risk prediction models overestimate surgical risk, particularly in octogenarians. The EuroSCORE II demonstrated better discriminatory accuracy for predicting operative mortality than STS, additive and logistic EuroSCORE in this population. Inclusion of new variables into these risk models, such as frailty, that are of particular interest in the elderly, may allow for more accurate prediction of true operative mortality and thus lead to improved decision making in this important group of patients.

\section{Abbreviations}

APPROACH: Alberta Provincial Project for Outcomes Assessment in Coronary Heart Disease; AUROC: Areas under the receiver operator characteristic; CABG: Coronary artery bypass grafting; EuroSCORE: European System for Cardiac Operative Risk Evaluation; STS: Society of Thoracic Surgeons

\section{Acknowledgements}

None.

\section{Availability of data and materials}

The data that support the findings of this study are available from the Alberta Provincial Project for Outcome Assessment in Coronary Heart Disease (APPROACH), http://www.approach.org/index.html.

\section{Authors' contributions}

JGYL contributed to data collection, data analysis/interpretation, drafting and critical revision of the article. MMG contributed to concept/design, critical revision and approval of the article. CMN contributed to data analysis and statistics. SAS contributed to concept/design, data collection, data analysis/ interpretation and drafting of the article. YSN contributed to data collection. SRM contributed to concept/design, data analysis/interpretation, critical revision and approval of the article. All authors read and approved the final manuscript.

\section{Ethics approval and consent to participate}

The University of Alberta Health Research Ethics Board has approved the waiver of patient consent for the Alberta Provincial Project for Outcome Assessment in Coronary Heart Disease (APPROACH) database (Pro00042669).

Consent for publication

Not applicable

Competing interests

The authors declare that they have no competing interests.

\section{Publisher's Note}

Springer Nature remains neutral with regard to jurisdictional claims in published maps and institutional affiliations.

\section{Author details}

${ }^{1}$ Division of Cardiac Surgery, Department of Surgery, Faculty of Medicine and Dentistry, University of Alberta, Edmonton, Canada. ${ }^{2}$ Mazankowski Alberta Heart Institute, Edmonton, Canada. ${ }^{3}$ Division of Cardiology, Department of Medicine, Faculty of Medicine and Dentistry, University of Alberta, Edmonton, Canada.

Received: 28 March 2017 Accepted: 18 October 2017

Published online: 02 November 2017

\section{References}

1. Graham MM, Ghali WA, Faris PD, Galbraith PD, Norris CM, Knudtson ML. Investigators ftAPPfOAiCHD: survival after coronary revascularization in the elderly. Circulation. 2002;105(20):2378-84.

2. Aziz A, Lee AM, Pasque MK, Lawton JS, Moazami N, Damiano RJ, Moon MR. Evaluation of revascularization subtypes in octogenarians undergoing coronary artery bypass grafting. Circulation. 2009;120(11 suppl 1):S65-9.

3. Kurlansky P. Do octogenarians benefit from coronary artery bypass surgery: a question with a rapidly changing answer? Curr Opin Cardiol. 2012;27(6):611-9.

4. Saxena A, Dinh DT, Yap CH, Reid CM, Billah B, Smith JA, Shardey GC, Newcomb AE. Critical analysis of early and late outcomes after isolated coronary artery bypass surgery in elderly patients. Ann Thorac Surg. 2011; 92(5):1703-11.

5. Nilsson J, Algotsson L, Höglund P, Lührs C, Brandt J. Comparison of 19 preoperative risk stratification models in open-heart surgery. Eur Heart J. 2006; 27(7):867-74.

6. Nashef SAM, Roques F, Hammill BG, Peterson ED, Michel P, Grover FL, Wyse $\mathrm{RKH}$, Ferguson TB. Validation of European system for cardiac operative risk evaluation (EuroSCORE) in north American cardiac surgery. Eur J Cardiothorac Surg. 2002;22(1):101-5.

7. Ghali WAKM. Overview of the Alberta provincial project for outcome assessment in coronary heart disease. On behalf of the APPROACH investigators. Can J Cardiol. 2000;16(10):1225-30.

8. Norris CM, Ghali WA, Knudtson ML, Naylor CD, Saunders LD: Dealing with missing data in observational health care outcome analyses. J Clin Epidemiol 2000, 53(4):377-383.

9. Zingone B, Pappalardo A, Dreas L. Logistic versus additive EuroSCORE. A comparative assessment of the two models in an independent population sample. Eur J Cardiothorac Surg. 2004;26(6):1134-40.

10. Statistics Canada: Annual demographic estimates: Canada, provinces and territories 2012. 
11. Ben-Gal Y, Finkelstein A, Banai S, Medalion B, Weisz G, Genereux P, Moshe S, Pevni D, Aviram G, Uretzky G. Surgical myocardial revascularization versus percutaneous coronary intervention with drug-eluting stents in octogenarian patients. Heart Surg Forum. 2012;15(4):E204-9.

12. Ghanta RK, Shekar PS, McGurk S, Rosborough DM, Aranki SF. Nonelective cardiac surgery in the elderly: is it justified? J Thorac Cardiovasc Surg. 2010; 140(1):103-9. 109 e101

13. Drury NENS. Outcomes of cardiac surgery in the elderly. Expert Rev Cardiovasc Ther. 2006;4(4):535-42

14. Gutacker N, Bloor K, Cookson R, Garcia-Armesto S, Bernal-Delgado E. Comparing hospital performance within and across countries: an illustrative study of coronary artery bypass graft surgery in England and Spain. Eur J Pub Health. 2015;25(Suppl 1):28-34.

15. Rangrass G, Ghaferi AA, Dimick JB. Explaining racial disparities in outcomes after cardiac surgery: the role of hospital quality. JAMA Surg. 2014;149(3):223-7.

16. Nicolini F, Contini GA, Fortuna D, Pacini D, Gabbieri D, Vignali L, Campo G, Manari A, Zussa C, Guastaroba P, et al. Coronary artery surgery versus percutaneous coronary intervention in octogenarians: long-term results. Ann Thorac Surg. 2015;99(2):567-74

17. Yanagawa B, Algarni KD, Yau TM, Rao V, Brister SJ. Improving results for coronary artery bypass graft surgery in the elderly. Eur J Cardiothorac Surg. 2012;42(3):507-12

18. Wang W, Bagshaw SM, Norris CM, Zibdawi R, Zibdawi M, MacArthur R. Association between older age and outcome after cardiac surgery: a population-based cohort study. J Cardiothorac Surg. 2014;9(1):177.

19. Baskett RBK, Ghali W, Norris C, Maas T, Maitland A, Ross D, Forgie R, Hirsch G. Outcomes in octogenarians undergoing coronary artery bypass grafting. CMAJ. 2005;127(9):1183-6.

20. Toumpoulis IK, Anagnostopoulos CE, DeRose JJ, Swistel DG. Does EuroSCORE predict length of stay and specific postoperative complications after coronary artery bypass grafting? Int J Cardiol. 2005;105(1):19-25.

21. Pinna Pintor P, Bobbio M, Colangelo S, Veglia F, Marras R, Diena M. Can EuroSCORE predict direct costs of cardiac surgery? Eur J Cardiothorac Surg. 2003;23(4):595-8.

22. Nashef SA, Roques F, Sharples LD, Nilsson J, Smith C, Goldstone AR, Lockowandt U. EuroSCORE II. Eur J Cardiothorac Surg. 2012;41(4):734-44. discussion 744-735

23. Lee DHBK, Martin BJ, Yip AM, Hirsch GM. Frail patients are at increased risk for mortality and prolonged institutional care after cardiac surgery. Circulation. 2010;121(8):973-8.

24. Sundermann S, Dademasch A, Praetorius J, Kempfert J, Dewey T, Falk V, Mohr FW, Walther T. Comprehensive assessment of frailty for elderly high-risk patients undergoing cardiac surgery. Eur J Cardiothorac Surg. 2011;39(1):33-7.

25. Rockwood K, Song X, MacKnight C, Bergman H, Hogan DB, McDowell I, Mitnitski A. A global clinical measure of fitness and frailty in elderly people CMAJ. 2005;173(5):489-95.

26. Graham MM, Galbraith PD, O'Neill D, Rolfson DB, Dando C, Norris CM. Frailty and outcome in elderly patients with acute coronary syndrome. Can J Cardiol. 2013;29(12):1610-5.

27. Wilson JF. Frailty-and its dangerous effects-might be preventable. Ann Intern Med. 2004;141(6):489-92.

28. Ravaglia G, Forti P, Lucicesare A, Pisacane N, Rietti E, Patterson C. Development of an easy prognostic score for frailty outcomes in the aged. Age Ageing. 2008;37(2):161-6.

29. Prudon I, Noyez L, van Swieten H, Scheffer GJ. Is gait speed improving performance of the EuroSCORE $\|$ for prediction of early mortality and major morbidity in elderly? J Cardiovasc Surg. 2014;57(4):592-7.

30. Afilalo J, Mottillo S, Eisenberg MJ, Alexander KP, Noiseux N, Perrault LP, Morin J-F, Langlois Y, Ohayon SM, Monette J, et al. Addition of frailty and disability to cardiac surgery risk scores identifies elderly patients at high risk of mortality or major morbidity. Circulation: Cardiovascular Quality and Outcomes. 2012;5(2):222-8.

31. Dupuis JY. Predicting outcomes in cardiac surgery: risk stratification matters? Curr Opin Cardiol. 2008;23(6):560-7.

32. Teo KK, Cohen E, Buller C, Hassan A, Carere R, Cox JL, Ly H, Fedak PW, Chan K, Legare JF, et al. Canadian cardiovascular society/Canadian Association of Interventional Cardiology/Canadian Society of Cardiac Surgery position statement on revascularization-multivessel coronary artery disease. Can J Cardiol. 2014;30(12):1482-91.

33. Barbero U, lannaccone M, d'Ascenzo F, Barbero C, Mohamed A, Annone U, Benedetto S, Celentani D, Gagliardi M, Moretti C, et al. 64 slice-coronary computed tomography sensitivity and specificity in the evaluation of coronary artery bypass graft stenosis: a meta-analysis. Int J Cardiol. 2016;216:52-7.

34. Geissler HJ, Holzl P, Marohl S, Kuhn-Regnier F, Mehlhorn U, Sudkamp M, de Vivie ER. Risk stratification in heart surgery: comparison of six score systems. Eur J Cardiothorac Surg. 2000;17(4):400-6.

\section{Submit your next manuscript to BioMed Central and we will help you at every step:}

- We accept pre-submission inquiries

- Our selector tool helps you to find the most relevant journal

- We provide round the clock customer support

- Convenient online submission

- Thorough peer review

- Inclusion in PubMed and all major indexing services

- Maximum visibility for your research

Submit your manuscript at www.biomedcentral.com/submit
) Biomed Central 